\title{
Proyeksi Masa Depan Kendaraan Listrik di Indonesia: Analisis Perspektif Regulasi dan Pengendalian Dampak Perubahan Iklim yang Berkelanjutan
}

\author{
Asrul Ibrahim Nur ${ }^{1}$ dan Andrian Dwi Kurniawan ${ }^{2}$
}

\begin{abstract}
Abstrak
Produksi dan penjualan kendaraan listrik di berbagai negara dan kawasan mengalami kemajuan yang sangat signifikan terutama di Tiongkok, Uni Eropa, dan Amerika Serikat. Indonesia cenderung tertinggal dari negara lain dalam penggunaan kendaraan listrik secara masif. Keberadaan kendaraan listrik yang mensubstitusi kendaraan berbahan bakar fosil akan berdampak pada berkurangnya emisi karbon. Masa depan kendaraan listrik sangat menjanjikan bagi pengendalian perubahan iklim yang berkelanjutan dengan syarat tertentu. Rekomendasi kebijakan naskah ini adalah peningkatan bauran energi terbarukan sebagai energi primer pada pembangkit listrik, pengaturan ketat kegiatan pertambangan terkhusus mineral bahan baku baterai, fasilitas dan sistem pengolahan limbah baterai wajib tersedia terlebih dahulu sebelum adanya peningkatan penggunaan kendaraan listrik secara signifikan, insentif fiskal bagi kendaraan listrik disertai pemberian disinsentif terhadap kendaraan konvensional, serta pengaturan komprehensif dan terintegrasi terkait kendaraan listrik sejak industri hulu sampai dengan hilir perlu ditetapkan dalam peraturan perundang-undangan yang memberikan kepastian hukum baik bagi investor, publik, dan bagi lingkungan.
\end{abstract}

Kata Kunci: kendaraan listrik, regulasi, perubahan iklim

\section{Abstract}

Sales and production of electric vehicles (EV) in various countries and regions have made significant progress, especially in China, the European Union and the United States. Indonesia tends to lag behind other countries in the massive use of electric vehicles. The existence of $E V$ that substitute fossil fuel vehicles will reduce carbon emissions. The future of EV is auspicious for sustainable climate change control under certain conditions. The policy recommendations of this article are to increase the mix of renewable energy as primary energy in power plants, strict regulation of mining activities, especially mineral raw materials for batteries, facilities and battery waste treatment systems must be available before there is a significant increase in the use of $E V$, fiscal incentives are carried out to $E V$ dan disincentives for conventional vehicles, as well as comprehensive and integrated arrangements related to EV from upstream to down-

\footnotetext{
${ }^{1}$ Penulis adalah Staf Pengajar Tidak Tetap pada Politeknik Energi dan Pertambangan Bandung.

${ }^{2}$ Penulis adalah Junior Sustainability Consultant pada Trisakti Sustainability Center dan Co Coordinator 2030 Youth Force Indonesia.
} 
stream industries need to be stipulated in-laws and regulations that provide legal certainty for investors, the public, and for the environment.

Keywords: electric vehicles, regulation, climate change

\section{Pendahuluan}

Perubahan iklim memiliki dampak yang nyata bagi bumi dan penghuninya. Suhu rata-rata secara global mengalami kenaikan $1^{\circ} \mathrm{C}$ dan berpengaruh pada peningkatan bencana alam. ${ }^{3}$ Khusus di Indonesia, hal tersebut salah satunya tercermin dari meningkatnya jumlah bencana alam setidaknya dalam sepuluh tahun terakhir. ${ }^{4}$ Pada 2009 jumlah bencana alam di Indonesia sebanyak 1.245 kejadian dan meningkat secara signifikan menjadi 3.814 kejadian pada 2019..$^{5}$ Menurut laporan yang disusun oleh Intergover- mental Panel on Climate Change (IPCC), ${ }^{6}$ perubahan iklim yang mengakibatkan kenaikan suhu bumi lebih jauh dapat berdampak pada kepunahan spesies dan keanekaragaman hayati di laut yang akan berpengaruh pada manusia.

Emisi Gas Rumah Kaca (GRK) menjadi faktor penentu semakin memanasnya suhu global, oleh karena itu negara-negara yang berkomitmen dalam Paris Agreement wajib mengurangi emisi GRK sesuai target yang telah ditetapkan. ${ }^{7}$ Indonesia

${ }^{3}$ Hans Nicholas Jong, "Indonesia Won't Sacrifice Economy for More Ambitious Emissions Cuts", https://news.mongabay.com/2020/04/indonesia-emissions-reduction-climate-carbon-economy-growth/, diakses 8 Februari 2021.

${ }^{4}$ United States Geological Survey (USGS) menyatakan bahwa peningkatan suhu muka bumi dan pemanasan global dapat menyebabkan terjadinya lebih banyak badai. Akibat lain yang mungkin timbul adalah meningkatnya permukaan air laut yang berpengaruh terhadap ekosistem disekitarnya. Lihat https://www.usgs.gov/faqs/how-can-climate-change-affect-natural-disasters-1?qt-news_science products=0\#qt-news_science_products, diakses 31 Maret 2021. Pendapat lain diungkapkan oleh United Nations International Strategy for Disaster Reduction Secretariat (UNISDR) yang menyebutkan bahwa perubahan iklim dapat meningkatkan degradasi lingkungan yang berpengaruh pada rapuhnya komunitas, lihat United Nations International Strategy for Disaster Reduction Secretariat, Climate Changer and Disater Risk Reduction, (Jenewa: Briefing Note 01, September 2008). hlm. 3.

${ }^{5}$ Badan Nasional Penanggulangan Bencana, https://www.bnpb.go.id/infografis/kejadian-bencana-tahun-2019, diakses tanggal 8 Februari 2021.

${ }^{6}$ Intergovermental Panel on Climate Change, Global Warming of $1.5^{\circ} \mathrm{C}$ an IPCC Special Report on the impacts of global warming of $1.5^{\circ} \mathrm{C}$ pre-industrial levels and related global greenhouse gas emission pathways, context of strengthening the global response to the threat of climate change, sustainable development, and efforts to eradicate poverty Summary for Policymakers, (Switzerland: Intergovermental Panel on Climate Change, 2018), hlm. 9-10.

${ }^{7}$ Indonesia telah meratifikasi Paris Agreement melalui Undang-Undang Nomor 16 Tahun 2016 tentang Pengesahan Paris Agreement to the United Nations Framework Convention on Climate Change (Persetujuan Paris atas Konvensi Kerangka Kerja Perserikatan Bangsa-bangsa Mengenai Perubahan Iklim) (Lembaran Negara Republik Indonesia Tahun 2016 Nomor 204, Tambahan Lembaran Negara Republik Indonesia Nomor 5939) 
Proyeksi Masa Depan Kendaraan Listrik di Indonesia: Analisis Perspektif Regulasi dan Pengendalian Dampak Perubahan Iklim yang Berkelanjutan

sebagai salah satu negara yang telah meratifikasi konvensi perubahan iklim juga terikat akan komitmen tersebut. Sebagai negara dengan penggunaan energi fosil yang cukup besar, Indonesia menghasilkan 1.637.156 juta ton emisi GRK pada 2018. Jumlah ini menempatkan Indonesia pada papan tengah peringkat negara penghasil emisi terbesar di dunia. ${ }^{9}$

Salah satu sektor yang menyumbang emisi sangat signifikan adalah energi, khususnya transportasi. Pada 2018, jumlah emisi GRK dari sektor energi mencapai 595 Juta $\mathrm{tCO}_{2} \mathrm{e}$ (ton setara $\left.\mathrm{CO}_{2}\right)^{10}$ dan dari jumlah tersebut sebanyak $28 \%$ berasal dari sektor transportasi. ${ }^{11}$ Fenomena ini tentu saja meresahkan banyak pihak, terlebih pertumbuhan kendaraan konvensional yang terus bertambah. Sepanjang 2018 dan 2019 tercatat tujuh juta lebih kendaraan bertambah baik itu roda dua dan empat. ${ }^{12}$

Inovasi kendaraan ramah lingkungan dan beremisi rendah adalah salah satu solusi yang dianggap dapat mengurangi emisi GRK dan berkorelasi terhadap pengendalian dampak perubahan iklim. Negara-negara di Eropa, Tiongkok, dan Amerika Serikat telah menggunakan kendaraan listrik secara masif. ${ }^{13}$

Kendaraan listrik ${ }^{14}$ di Indonesia terbilang baru dan masih belum sepenuhnya mendapatkan perhatian publik. Salah satu peristiwa yang pernah menjadi sorotan adalah ketika momentum Konferensi Tingkat Tinggi (KTT) APEC Tahun 2013 di Bali. Menteri Badan Usaha Milik Negara saat itu, Dahlan Iskan, mempromosikan mobil listrik karya Ricky Elson, seorang inovator mobil listrik yang lama

${ }^{8}$ Direktorat Jenderal Pengendalian Perubahan Iklim, Laporan Inventarisasi Gas Rumah Kaca dan Monitoring, Pelaporan, dan Verifikasi 2020, (Jakarta: Direktorat Jenderal Pengendalian Perubahan Iklim, Kementerian Lingkungan Hidup dan Kehutanan Republik Indonesia, 2020), hlm 41.

${ }^{9}$ Yosepha Pusparisa, "Rapor Indonesia Menahan Laju Perubahan Iklim", https:// katadata.co.id/ arsip/analisisdata/602de2e0ee7f6/rapor-indonesia-menahan-laju-perubahan-iklim, diakses 31 Maret 2021.

${ }^{10}$ Direktorat Jenderal Pengendalian Perubahan Iklim, Statistik 2019, (Jakarta: Direktorat Jenderal Pengendalian Perubahan Iklim, Kementerian Lingkungan Hidup dan Kehutanan Republik Indonesia, 2020), hlm 91.

${ }^{11}$ Julius Christian Adiatma dan Idoan Marciano, Ringkasan untuk Para Pembuat Kebijakan: Peranan Kendaraan Listrik dalam Dekarbonisasi Sektor Transportasi Darat Indonesia, (Jakarta: Institute for Essential Services Reform, 2020), hlm 9.

${ }^{12}$ Badan Pusat Statistik, "Perkembangan Jumlah Kendaraan Bermotor Menurut Jenis (Unit) 20172019", https://www.bps.go.id/indicator/17/57/1/jumlah-kendaraan-bermotor.html, diakses 2 Februari 2021.

${ }^{13}$ Erika Farkas Csamangó, The Legal Environment of Electromobility in Hungary. (Journal of Agricultural and Environmental Law, 2020), hlm 182.

${ }^{14}$ Kendaraan listrik dalam naskah ini mencakup Pure Electric Vehicle (PHV) atau Battery Electric Vehicle (BEV) dan Hybrid Electric Vehicle (HEV). Bacaan lebih lanjut Ning Ding, K. Prasad, dan T.T.Lie, "The Electric Vehicle: a Review", International Journal of Electric and Hybrid Vehicle, Januari 2017). 
bermukim di Jepang. Sejak 2012, mobil listrik disosialisasikan dengan gencar, namun usahanya kandas karena mobil listrik tersebut dianggap tidak layak jalan oleh instansi terkait. ${ }^{15}$

Mobil listrik kembali mendapatkan perhatian serius saat Presiden Joko Widodo menetapkan Peraturan Presiden Nomor 55 Tahun 2019 tentang Percepatan Program Kendaraan Bermotor Listrik Berbasis Baterai (Battery Electric Vehicle) untuk Transportasi Jalan (Perpres No. 55 Tahun 2019). Konsideran pembentukan regulasi tersebut menyebutkan aspek ketahanan dan konservasi energi, penurunan emisi GRK, serta penguasaan teknologi industri menjadi latar belakang penerbitannya.

Regulasi ini diharapkan mampu menciptakan iklim yang kondusif bagi perkembangan produksi dan penggunaan kendaraan listrik oleh publik. Populasi kendaraan listrik di Indonesia hingga bulan September 2020 hanya sebanyak 2.278 unit, jumlah ini merupakan jumlah sertifikasi untuk kendaraan listrik yang diterbitkan oleh Kementerian Perhubungan. ${ }^{16}$ Jumlah ini tentu sangat jauh jika dibandingkan dengan jumlah kendaraan listrik yang ada di Eropa (khususnya Kawasan Skandinavia) yang mencapai 1,2 juta unit atau Tiongkok yang mencapai 2,5 juta unit pada 2019. ${ }^{17}$

Jumlah kendaraan listrik, khususnya mobil, di Indonesia yang tidak sebanding dengan kendaraan berbahan bakar fosil ini sebenarnya tercermin dari target yang tercantum dalam Rencana Umum Energi Nasional (RUEN) yaitu sebanyak 2.200 unit kendaraan roda empat dan 2,1 juta unit kendaraan roda dua yang wajib dicapai setidaknya sampai tahun 2050. ${ }^{18}$

Perpres No. 55 Tahun 2019 memberikan angin segar dan harapan agar kendaraan listrik semakin berkembang di Indonesia. Selain itu, diharapkan bertumbuhnya populasi kendaraan listrik berbanding lurus dengan pengurangan emisi GRK sebagai bagian dari pengendalian dampak perubahan iklim di Indonesia. Mengarusutamakan penggunaan kendaraan listrik di Indonesia bukan suatu hal yang mudah. Banyak tantangan dan hambatan dalam berbagai aspek seperti lingkungan, tata kelola, kultural, ekonomi bahkan psikologis. Meskipun

${ }^{15}$ Dahkan Iskan, "Manufacturing Hope 123: Main-Main Nasib Ahli yang Mahal", https://www. jpnn.com/news/main-main-nasib-ahli-yang-mahal?page=3, diakses 2 Februari 2021.

${ }^{16}$ Ruly Kurniawan, "Pelan tapi Pasti, Jumlah Kendaraan Listrik di Indonesia Mencapai 2.278 Unit", https://otomotif.kompas.com/read/2020/09/09/090200215/pelan-tetapi-pasti-populasi-kendaraan-listrik-di-indonesia-2278-unit, diakses 2 Februari 2021. hlm. 4-5.

${ }^{17}$ Jamie Hamilton, et al, Electric Vehicles Setting a Course for 2030 (London: Deloitte Insights, 2020),

${ }^{18}$ Lampiran I Peraturan Presiden Nomor 22 Tahun 2017 tentang Rencana Umum Energi Nasional (Lembaran Negara Republik Indonesia Tahun 2017 Nomor 43). 
Proyeksi Masa Depan Kendaraan Listrik di Indonesia: Analisis Perspektif Regulasi dan Pengendalian Dampak Perubahan Iklim yang Berkelanjutan

demikian, meningkatkan populasi kendaraan masa depan ini menjadi kewajiban bagi Indonesia jika tidak ingin tertinggal dengan negara lain baik dalam teknologi transportasi, pertumbuhan ekonomi dan juga reduksi emisi GRK.

Dampak perubahan iklim yang sudah nyata di Indonesia seharusnya menjadi momentum untuk mengubah regulasi agar dapat beradaptasi dan bahkan mengendalikannya. Meskipun demikian, terdapat tantangan dan hambatan multiaspek terkait regulasi hijau, salah satunya terkait pengembangan kendaraan listrik.

Tulisan ini akan mengulas prospek kendaraan listrik sebagai salah satu solusi untuk mengurangi emisi GRK sehingga dapat mengendalikan dampak perubahan iklim secara berkelanjutan. Pertama adalah pembahasan mengenai korelasi kendaraan listrik dan pengendalian dampak perubahan iklim. Bagian ini akan membahas mengenai sejarah kendaraan listrik, perkembangan regulasi kendaraan listrik di berbagai negara, dan prasyarat kendaraan listrik sebagai solusi atau bahkan masalah baru. Selanjutnya, pada bagian kedua akan dibahas mengenai ekosistem regulasi kendaraan listr- ik di Indonesia yang meliputi Peraturan Presiden (Perpres) dan peraturan teknis dalam bentuk Peraturan Menteri. Bagian pembahasan akhir akan diulas mengenai masa depan kendaraan listrik dan pengendalian dampak perubahan iklim di Indonesia. Sebagai penutup, naskah ini akan memberikan beberapa rekomendasi kebijakan terkait kendaraan listrik.

\section{Kendaraan Listrik dan Pengendali- an Dampak Perubahan Iklim}

Kendaraan listrik sebenarnya bukan teknologi yang benar-benar baru. Pada 1828 seorang biarawan Benediktin sekaligus insinyur Hongaria, Jedlik Anyos, telah mengembangkan jenis kendaraan ini. ${ }^{19}$ Meskipun demikian, pada akhirnya karena dianggap tidak komersil maka pengembangan kendaraan oleh penemu asal Eropa Tengah tersebut dihentikan.

Pada perkembangan selanjutnya, kendaraan listrik banyak dilakukan oleh ilmuwan di luar Hongaria, di antaranya Thomas Parker (Inggris, 1884), ${ }^{20}$ Camille Jenatzy (Belgia, 1899), ${ }^{21}$ serta A.L Ryker dan William Morrison (Amerika Serikat, 1891). ${ }^{22}$ Tingginya harga produksi terutama baterai dan penemuan banyak sumur minyak di berbagai belahan dunia yang

\footnotetext{
${ }^{19}$ Erika Farkas Csamangó, Op.Cit.

${ }^{20}$ Joeri van Mierlo, "The World Electric Vehicle Journal, The Open Access Journal for the e-Mobility Scene", World Electric Vehicle Journal, (2018), hlm. 1.

${ }^{21}$ Ibid.

${ }^{22}$ C. C. Chan, The Rise and Fall of Electric Vehicles in 1828-1930: Lessons Learned, (Proceedings of the IEEE, Vol. 101, No.1, Januari, 2013), hlm. 2017
} 
berimplikasi semakin murahnya harga bahan bakar minyak pada saat itu membuat industri kendaraan listrik menjadi tidak ekonomis dan semakin ditinggalkan. ${ }^{23}$

Kelangkaan sumber minyak bumi dan semakin parahnya dampak perubahan iklim memutarbalikkan anggapan bahwa kendaraan listrik tidak layak digunakan karena alasan ekonomis. Berbagai studi membuktikan penggunaan kendaraan listrik lebih ekonomis daripada kendaraan berbahan bakar fosil,$^{24}$ selain itu juga secara signifikan mengurangi emisi. ${ }^{25}$ Oleh karena itu, banyak negara mulai mengembangkan teknologi kendaraan listrik dan mengenalkannya secara luas kepada publik.

\section{A. Perkembangan Regulasi Kendara- an Listrik di berbagai Negara}

Secara umum saat ini episentrum produksi dan konsumsi kendaraan listrik berada pada tiga kawasan, yaitu Tiongkok, Eropa, dan Amerika Serikat. Separuh penjualan kendaraan listrik dunia pada tahun 2019 dikuasai oleh Tiongkok, lalu diikuti oleh Uni Eropa dan Amerika Serikat. ${ }^{26}$ Keunggulan Tiongkok dalam penggunaan kendaraan listrik dimulai pada tahun 2001 dengan meluncurkan Program Nasional Penelitian dan Pengembangan Teknologi Tinggi. ${ }^{27}$ Kemudian pada tahun 2009 dilanjutkan dengan kebijakan "Kendaraan Energi Baru" secara nasional, lalu diikuti oleh pemberian insentif, subsidi, dan mulai mewajibkan penggunaan kendaraan hibrida. Regulasi yang mengatur kendaraan listrik ini bukan hanya ada di level nasional tetapi juga hingga daerah. ${ }^{28}$

Motivasi Tiongkok untuk mengembangkan teknologi kendaraan listrik tidak terlepas dari keinginan kuat pemerintahnya untuk menurunkan tingkat polusi udara dan emisi. ${ }^{29}$ Kebijakan untuk mengurangi polusi dan emisi tersebut ditetapkan dalam skala nasional dan lokal. Dukungan dan aksi nyata pemerintah lokal, khususnya kota besar di Tiongkok membantu meningkatkan penjualan

${ }^{23}$ Sharon L. Poczter dan Luka M. Jankovic, "General Motors: The Electric Revolution", Journal of Business Case Studies, (Second Quarter 2014), hlm. 185.

${ }^{24}$ Patrick Moriarty dan Stephen Jia Wang, Can Electric Vehicles Deliver Energy and Carbon Reductions?, (The $8^{\text {th }}$ International Confrence on Applied Energy Proceedings, 2017), hlm. 2938.

${ }^{25}$ Julius Christian Adiatma dan Idoan Marciano, Op.Cit. hlm. 17.

${ }^{26}$ International Energy Agency, “Global EV Outlook 2020: Entering the Decade of Electric Drive?", International Energy Agency, (2020), hlm. 44.

${ }^{27}$ Wang Tao, "Recharging China's Electric Vehicle Plocy", Carnegie-Tsinghua Center for Global Policy, Policy Outlook, (2013), hlm. 2.

${ }^{28}$ Hui He et al., Assessment of Electric Car Promotion Policies in Chinese Cities, (Washington DC: International Council on Clean Transportation, 2018), hlm. 12-13.

${ }^{29}$ Sabrina Howell, et.al., Leapfrogging or Stalling Out? Electric Vehicles in China, (Cambridge: Harvard Kennedy School, 2015), hlm. 4. 
Proyeksi Masa Depan Kendaraan Listrik di Indonesia: Analisis Perspektif Regulasi dan Pengendalian Dampak Perubahan Iklim yang Berkelanjutan

kendaraan listrik secara signifikan. Pada tahun 2020 sebanyak $42 \%$ pemilik kendaraan listrik terdapat pada 25 kota di Tiongkok dengan Shanghai sebagai kota dengan populasi kendaraan listrik terbanyak. ${ }^{30}$

Berbeda dengan Tiongkok, Uni Eropa sebagai entitas internasional yang terdiri dari banyak negara anggota menetapkan beberapa kebijakan organisasi yang kemudian menjadi kebijakan nasional masing-masing anggotanya. Perkembangan kendaraan listrik di Uni Eropa tidak terlepas dari komitmen untuk mengurangi emisi GRK, polusi udara, dan polusi suara yang berimplikasi pada kualitas lingkungan dan kesehatan. ${ }^{31}$

Untuk mendukung komitmen tersebut, Uni Eropa pada 2016 kemudian menetapkan dokumen A European Strategy for Low-Emission Mobility. Dokumen ini secara umum memperkenalkan kerangka kerja untuk mempromosikan kendaraan rendah emisi di kawasan. Motivasi ini merupakan salah satu upaya untuk memodernisasi ekonomi, menurunkan emisi dari sektor transportasi, dan bagian komitmen Uni Eropa dalam melaksanakan Paris Agreement. ${ }^{32}$ Uni Eropa juga menetapkan the 2018/1999 Regulation (EU) of The European Parliament and of The Council of 11 December 2018 on the Governance of the Energy Union and Climate Action dan the Directive (EU) 2018/2001 of The European Parliament and of The Council of 11 December 2018 on the promotion of the use of energy from renewable sources. ${ }^{33}$ Kebijakan ini ditindaklanjuti oleh masing-masing negara anggota dengan menetapkan regulasi terkait kendaraan listrik.

Kunci dari keberhasilan negara-negara Uni Eropa meningkatkan penggunaan kendaraan listrik adalah dengan menetapkan regulasi yang memberikan insentif fiskal dan non fiskal (berimplikasi pada penurunan harga) secara signifikan, jaringan pengisian baterai yang luas dan masif, serta promosi dan edukasi kepada publik mengenai keuntungan menggunakan kendaraan listrik. Direktif Uni Eropa ini meningkatkan penetrasi kendaraan listrik di Uni Eropa secara signifikan

${ }^{30}$ Hui He, "China New Energy Vehicle Market and Policies", The International Council on Clean Transportation, (2020), hlm. 15.

${ }^{31}$ Maria Niestadt dan Amalie Bjornavold, "Electric Road Vehicles in the European Union: Trends, Impacts, and Policies", European Parliament Briefing, (April 2019), hlm. 4.

${ }^{32}$ European Commission, "A European Strategy for Low-Emission Mobility", European Commission, Communication from the Commission to the European Parliament, The Council, The European Economic and Social Committee and the Committee of the Regions, (2016), hlm. 13.

${ }_{33}$ Terkait dengan kendaraan listrik, dokumen hukum ini memberikan arahan bagi negara-negara anggota Uni Eropa untuk mempromosikan penggunaan kendaraan listrik kepada warga negaranya dan juga penggunaan energi terbarukan sebagai sumber pembangkit listrik yang akan digunakan untuk pengisian baterai kendaraan listrik sebagai moda transportasi. Dokumen ini dapat diakses di https:/ / eur-lex.europa.eu/legal-content/EN/TXT/PDF/?uri=CELEX:32018L2001\&from=fr 
dari $2 \%$ menjadi $61 \%$ dalam tempo dua tahun. ${ }^{34}$

Tidak seperti Uni Eropa yang terdiri dari banyak negara anggota dan memiliki kedaulatan masing-masing, kondisi regulasi terkait kendaraan listrik di Amerika Serikat hampir sama dengan Tiongkok yaitu terdapat regulasi pada level nasional (federal) dan lokal (negara bagian). Sebanyak 47 dari 50 negara bagian di Amerika Serikat telah memiliki regulasi lokal untuk mempromosikan penggunaan kendaraan listrik kepada publik. ${ }^{35}$

Regulasi kendaraan listrik pada tingkat federal bermula sejak Badan Perlindungan Lingkungan Hidup Amerika Serikat (US EPA) pada tahun 2012 menetapkan pengurangan emisi GRK. Selanjutnya insentif berupa pinjaman dan hibah diberikan kepada perusahaan yang mengembangkan teknologi baterai kendaraan listrik, insentif perpajakan juga diberikan dalam skala federal. Dana penelitian dan pengembangan terkait kendaraan listrik juga digulirkan. Selain itu, edukasi dan promosi kepada publik juga dilaksanakan dengan gencar. ${ }^{36}$
Kebijakan lain yang juga diambil oleh pemerintah federal Amerika Serikat adalah dengan membantu elektrifikasi moda transportasi milik pemerintah kota (municipal) dan memberikan insentif non fiskal seperti tarif parkir, biaya registrasi, dan pengurangan biaya tes emisi. ${ }^{37}$ Berbagai kebijakan federal dan lokal tersebut cukup meningkatkan penjualan kendaraan listrik bahkan pada 2018 mencapai hingga $80 \%$. Meskipun demikian pada tahun 2020 tren penjualan menurun akibat ketidakpastian ekonomi yang ditimbulkan pandemi COVID-19.38

\section{B. Kendaraan Listrik: Solusi atau Masalah Baru bagi Perubahan Iklim?}

Tiongkok, Uni Eropa, dan Amerika Serikat sebagai pemimpin produksi dan pasar kendaraan listrik memiliki latar belakang yang sama, yaitu kepedulian akan lingkungan dan dampak perubahan iklim. Dengan kata lain, regulasi yang mengatur tentang kendaraan listrik sangat memperhatikan aspek keberlanjutan (sustainability) dan menyadari bahwa bahan bakar fosil memiliki dampak negatif

${ }^{34}$ Sandra Wappelhorst, et.al., Analyzing Policies to Grow the Electric Vehicle Market in European Cities (Berlin: International Council on Clean Transportation White Paper, 2020), hlm. 27.

${ }^{35}$ International Energy Agency, "United States-Policies and Legislation", http://www.ieahev. org/by-country/united-states-policy-and-legislation/. Diakses 15 Februari 2021.

${ }^{36}$ Deborah Gordon, et.al., Policy Priorities for Advancing the U.S. Electric Vehicle Market, (Washington D.C: Carnegie Endowment for International Peace Publication Department, 2012), hlm. 6.

${ }^{37}$ Bill Canis, et.al., "Vehicle Electrification: Federal and State Issues Affecting Deployment", Congressional Research Service, (3 Juni 2019), hlm. 16.

${ }^{38}$ McKinsey, McKinsey Electric Vehicle Index: Europe Cushions a Global Plunge in EV Sales, https:// www.mckinsey.com/industries/automotive-and-assembly/our-insights/mckinsey-electric-vehicleindex-europe-cushions-a-global-plunge-in-ev-sales\#, diakses 15 Februari 2021. 
Proyeksi Masa Depan Kendaraan Listrik di Indonesia: Analisis Perspektif Regulasi dan Pengendalian Dampak Perubahan Iklim yang Berkelanjutan

terhadap lingkungan. ${ }^{39}$ Kendaraan listrik sebenarnya dapat menjadi salah satu solusi bagi pengendalian dampak perubahan iklim, dengan salah satunya dapat membantu mengurangi emisi GRK dari sektor transportasi. Selain itu, keberadaan kendaraan listrik wajib didukung dengan ketersediaan listrik yang dihasilkan oleh pembangkit listrik dari energi terbarukan. $^{40}$

Jika tidak memenuhi persyaratan tersebut, maka kehadiran kendaraan listrik justru akan menimbulkan masalah baru bagi perubahan iklim. Konsumsi listrik yang meningkat di tengah masih tingginya penggunaan bahan bakar fosil sebagai energi primer pembangkit listrik akan membuat peningkatan emisi dari sektor energi. Oleh karena itu, ketersediaan pembangkit listrik bersumber energi ramah lingkungan menjadi syarat wajib bagi penggunaan kendaraan listrik secara masif.

Sebagai negara yang meratifikasi Paris Agreement, Indonesia memiliki komit- men untuk menurunkan emisi GRK sesuai target yang dituangkan dalam $\mathrm{Na}$ tionally Determined Contribution (NDC). Dalam dokumen NDC Indonesia bulan November 2016 disebutkan bahwa target penurunan emisi GRK pada tahun 2030 sebesar 29\% dengan kemampuan sendiri dan $41 \%$ dengan dukungan internasional. Angka ini adalah sebesar 834 juta ton $\mathrm{CO}_{2} \mathrm{e}$ pada target unconditional (CM1) dan sebesar 1.081 juta ton $\mathrm{CO}_{2} \mathrm{e}$ pada target conditional (CM2). ${ }^{41}$

Penggunaan kendaraan listrik yang masif tentu akan membantu memenuhi target tersebut, terutama penurunan emisi GRK dari sektor energi. Proyeksi yang dilakukan oleh Institute for Essential Sevice Reform (IESR) ${ }^{42}$ menunjukkan bahwa kontribusi kendaraan listrik dalam penurunan emisi GRK harus disertai transformasi sumber energi primer yang digunakan oleh pembangkit listrik. ${ }^{43}$ Untuk jangka pendek pada skenario ambisius penetrasi kendaraan listrik, penurunan emisi GRK mencapai 10 juta ton $\mathrm{CO}_{2}$. Angka ini memang hanya 3\%

\footnotetext{
${ }^{39}$ Idoan Marciano, Mengembangkan Ekosistem Kendaraan Listrik di Indonesia Pelajaran dari Pengalaman Amerika Serikat, Norwegia, dan Cina, (Jakarta: Institute for Essential Services Reform, 2021), hlm. 23 dan 29.

${ }^{40}$ Patrick Moriarty dan Stephen Jia Wang, Op.Cit. hlm. 2987.

${ }^{41}$ Direktorat Jenderal Pengendalian Perubahan Iklim, Strategi Implementasis NDC (Nationally Determined Contribution), (Jakarta: Direktorat Jenderal Pengendalian Perubahan Iklim, Kementerian Lingkungan Hidup dan Kehutanan, 2017), hlm. 9.

${ }^{42}$ Julius Christian Adiatma dan Idoan Marciano, The Role of Electric Vehicles in decarbonizing Indonesia's Road Transport Sector, (Jakarta: Institute for Essential Services Reform, 2020), hlm. 39.

Menurut data yang dirilis Direktorat Jenderal Energi Terbarukan, Kementerian Energi dan Sumber Daya Mineral hingga 2020 bauran energi terbarukan pada pembangkit listrik mencapai 14,21\%. Jauh dari target yang ditetapkan yaitu 23\% pada tahun 2025. Sumber https://ebtke.esdm.go.id/ post/2020/07/28/2593/fact.sheet.update.kinerja.subsektor.ebtke.tahun.2020, diakses 10 April 2021.
} 
dari target yang ditetapkan oleh NDC, meskipun demikian dalam jangka panjang penurunan emisi ini menjanjikan secara signifikan.

Masalah lain yang dapat timbul dari kendaraan listrik adalah terkait produksi dan limbah baterai. Sebagai salah satu komponen utama, baterai memiliki peranan vital dan menjadi penentu harga jual kendaraan listrik. ${ }^{44}$ Bahan baku dari baterai tersebut adalah bahan tambang mineral seperti lithium, nikel, kobalt, dan mangan. Oleh karena itu, penggunaan kendaraan listrik yang masif tidak bisa menghindari peningkatan permintaan keempat mineral tersebut ${ }^{45}$ dan berimplikasi pada kegiatan pertambangannya. Solusi untuk menyelamatkan bumi ternyata tetap harus mengorbankan bagian bumi yang lain.

Dampak negatif lain yang akan timbul adalah terkait pengolahan limbah baterai kendaraan listrik yang mengandung bahan berbahaya dan beracun (B3) seperti nikel beracun dan lanthanum. ${ }^{46}$ Untuk mengatasinya maka fasilitas daur ulang limbah baterai menjadi sebuah ke- wajiban yang harus diwujudkan. Selain itu, penukaran atau pembelian baterai baru juga mesti diatur dengan baik agar dapat mengendalikan potensi jumlah limbah baterai. Produsen kendaraan listrik juga perlu memikirkan mengenai biaya lingkungan untuk memitigasi potensi kerusakan lingkungan, deteksi kerusakan lingkungan, pengolahan limbah, serta aktivitas untuk memperbaiki lingkungan. ${ }^{47}$

Dengan demikian, tiga syarat yang wajib dipenuhi secara kumulatif untuk dapat memaksimalkan potensi kendaraan listrik dalam mengendalikan dampak perubahan iklim adalah pembangkit listrik dengan sumber energi primer yang ramah lingkungan, pengendalian kegiatan pertambangan mineral sebagai bahan baku baterai, dan penyediaan fasilitas pengolahan limbah baterai. Regulasi tanpa ketiga hal tersebut tidak akan menjadikan kendaraan listrik sebagai solusi, justru dapat menjadi masalah baru bagi pengendalian dampak perubahan iklim.

\footnotetext{
${ }^{44}$ David Coffin dan Jeff Horowitz, "The Supply Chain for Electric Vehicle Batteries", United States International Trade Commision, Journal of International Commerce and Economics, (2018), hlm. 4.

${ }^{45} \mathrm{Xu}, \mathrm{C}$., Dai, Q., Gaines, L. et al., "Future material demand for automotive lithium-based batteries". Communication Materials, (2020). https:/ / doi.org/10.1038/s43246-020-00095-x

${ }^{46}$ Yuanan Hu, et.al., Retired Electric Vehicle (EV) Batteries: Integrated Waste Management and Research Needs, (American Chemical Society, Environmental Science and Technology, 2017), hlm. 1028.

47 Arif Dwi Santoso, "Penerapan Biaya Lingkungan dalam Perlindungan Sumberdaya Alam dan Kelestarian Lingkungan”, Jurnal Rekayasa Lingkungan, Vol. 11, No. 1, (Juni 2018), hlm. 1-6.
} 
Proyeksi Masa Depan Kendaraan Listrik di Indonesia: Analisis Perspektif Regulasi dan Pengendalian Dampak Perubahan Iklim yang Berkelanjutan

\section{Ekosistem Regulasi Kendaraan}

\section{Listrik di Indonesia}

\section{A. Peraturan Presiden sebagai Regulasi Utama}

Ibarat sebuah organisme biologis, kendaraan listrik membutuhkan ekosistem dan lingkungan yang mendukung untuk tumbuh dan berkembang dengan baik. Langkah yang dilakukan oleh pemerintah dengan menetapkan Perpres No. 55 Tahun 2019 dapat dikatakan tepat, meskipun cukup terlambat. Regulasi tersebut menjadikan kehadiran kendaraan listrik di Indonesia memiliki landasan hukum yang cukup kuat. Dipilihnya bentuk peraturan perundang-undangan berupa Peraturan Presiden dikarenakan tidak adanya Undang-Undang yang secara eksplisit mengamanatkan untuk pengembangan kendaraan listrik.

Jika menelisik dari tata cara pembentukan peraturan perundang-undangan, Perpres merupakan bentuk peraturan perundang-undangan yang memiliki materi muatan dan fungsi tertentu. Materi muatan yang diatur oleh Perpres adalah materi yang diperintahkan oleh Undang-Undang, untuk melaksanakan Peraturan
Pemerintah, atau untuk menyelenggarakan kekuasaan pemerintahan. ${ }^{48}$ Maria Farida Indrati, Guru Besar Fakultas Hukum Universitas Indonesia, berpendapat bahwa setidaknya terdapat tiga fungsi Perpres, yaitu untuk menyelenggarakan pengaturan secara umum dalam rangka penyelenggaran kekuasaan pemerintahan, pengaturan lebih lanjut ketentuan dalam Peraturan Pemerintah baik secara eksplisit maupun implisit disebut. ${ }^{49}$

Perpres No. 55 Tahun 2019 secara jelas bukan dibentuk untuk melaksanakan perintah Undang-Undang atau Peraturan Pemerintah, melainkan untuk melaksanakan kekuasaan pemerintahan dalam hal ini dilaksanakan oleh Presiden sebagai kepala pemerintahan. Dengan kata lain, Perpres yang mengatur kendaraan listrik dapat dikategorikan sebagai Perpres yang mandiri ${ }^{50}$ dan tidak dibentuk untuk melaksanakan perintah peraturan perundang-undangan yang lebih tinggi hierarkinya namun sebagai instrumen Presiden dalam menyelenggarakan kekuasaan pemerintahan yang diberikan oleh Undang-Undang Dasar.

Sistem presidensial yang dianut oleh Indonesia memiliki implikasi otoritas

\footnotetext{
${ }^{48}$ Indonesia, Undang-Undang Nomor 12 Tahun 2011 tentang Pembentukan Peraturan Perundang-undangan, LN Tahun 2011 No. 82, TLN No. 5234, Ps. 13.

${ }^{49}$ Maria Farida Indrati S., Ilmu Perundang-undangan Jenis, Fungsi, dan Materi Muatan, (Yogyakarta: Penerbit Kanisius, 2019), hlm. 223-224.

${ }^{50}$ Prischa Listiningrum, “Eksistensi dan Kedudukan Peraturan Presiden dalam Hierarki Peraturan Perundang-undangan di Indonesia”, Jurnal Arena Hukum, Vol. 12, No. 2, (Agustus 2019), hlm. 342.
} 
yang dimiliki Presiden cukup besar. ${ }^{51}$ Kondisi tersebut memiliki sisi positif dan negatif yang saling mempengaruhi satu sama lain. Sisi positif dari besarnya otoritas yang dimiliki kepala pemerintahan adalah Presiden dapat menetapkan peraturan perundang-undangan baik itu Peraturan Pemerintah Pengganti Undang-Undang, Peraturan Pemerintah, Peraturan Presiden, peraturan kebijakan (beleidsregel), ketetapan administrasi negara (beschikking), dan perencanaan (plannen) ${ }^{52}$ secara leluasa untuk merealisasikan janji politik dan program pemerintahannya. Sisi negatif yang harus dihadapi adalah kondisi demikian membuat pergantian rezim pemerintahan akan menimbulkan ketidakpastian terhadap kesinambungan program pemerintahan sebelumnya.

Keberadaan kendaraan listrik seharusnya bukan hanya menjadi program pemerintahan tetapi sebaiknya menjadi program negara, oleh karena itu instrumen hukum yang digunakan dapat lebih kuat dari Perpres. Hal ini untuk menjamin kesinambungan pertumbu- han kendaraan listrik di Indonesia yang dalam jangka panjang akan berpengaruh terhadap pengurangan emisi GRK dari sektor transportasi secara signifikan. Kestabilan dan kesinambungan juga sangat dibutuhkan dalam perspektif investasi, terlebih industri kendaraan listrik membutuhkan modal yang tidak sedikit. Oleh karena itu, kepastian hukum berupa regulasi yang mengatur harus kuat dan tidak mudah berganti akibat beralihnya rezim atau pemerintahan. ${ }^{53}$

Disamping itu, Indonesia sangat menarik bagi investor karena memiliki jumlah penduduk yang besar dan sumber daya alam yang melimpah. Salah satu perusahaan global yang memproduksi kendaraan listrik, Tesla, dikabarkan tertarik untuk berinvestasi di Indonesia dalam bidang energi terbarukan dan kendaraan listrik. ${ }^{54}$ Meskipun pada perkembangan selanjutnya intensi produsen raksasa kendaraan listrik tersebut terganjal lemahnya aspek environmental, social, dan governance (ESG) pada praktik investasi perusahaan di Indonesia. ${ }^{55}$

${ }^{51}$ Fajlurrahman Jurdi, “Format Kekuasaan Presiden dalam UUD NRI 1945 (Relasi Horizontal dan Vertikal kekuasaan Presiden dalam Sistem Presidensial)", Jurnal Amanna Gappa, Vol. 25, No. 2, (September 2017), hlm. 43.

${ }^{52}$ Bagir Manan, Teori dan Politik Konstitusi, (Yogyakarta: FH UII Press, 2003), hlm. 229.

${ }^{53}$ Amanda Perry, "An Ideal Legal System for Attracting Foreign Direct Investment? Some Theory and Reality", American University International Law Review, Vol. 15, Issue 6, (2000), hlm. 1631.

${ }^{54}$ Reuters, "Indonesia says in early talks with Tesla on potential investment", https://www.reuters.com/article/us-tesla-indonesia/indonesia-says-in-early-talks-with-tesla-on-potential-investment-idINKBN26Q16I, diakses 11 Februari 2021.

Vincent Fabian Thomas, "Potensi Investasi Tesla Terganjal Karena Indonesia Tak Ramah ESG", https://tirto.id/potensi-investasi-tesla-terganjal-karena-indonesia-tak-ramah-esg-gaa9, diakses 11 Februari 2021. 
Proyeksi Masa Depan Kendaraan Listrik di Indonesia: Analisis Perspektif Regulasi dan Pengendalian Dampak Perubahan Iklim yang Berkelanjutan

Kehadiran regulasi yang stabil dan berkesinambungan juga dibutuhkan untuk menciptakan kondisi penerimaan publik terhadap kendaraan listrik. Transformasi energi semacam ini pernah dialami oleh Indonesia pada tahun 2007, yaitu konversi minyak tanah ke gas elpiji. Pada awalnya terdapat resistensi besar di masyarakat, bahkan kerap kali terjadi ledakan pada masa adaptasi penggunaan gas di rumah tangga. ${ }^{56}$ Namun demikian, pada akhirnya karena tidak ada pilihan lain bagi masyarakat selain beradaptasi maka kebijakan ini dapat mengubah kebiasaan masyarakat dalam penggunaan minyak tanah menjadi gas.

Transformasi dari kendaraan berbahan bakar fosil ke kendaraan listrik memiliki dimensi perubahan yang jauh lebih besar, karena bukan saja mengubah kebiasaan tetapi juga budaya masyarakat dalam menggunakan kendaraan dan bahan bakarnya. Oleh karena itu, mutlak diperlukan regulasi dalam bentuk yang kuat dan menjamin stabilitas perubahan.

\section{B. Kebijakan Teknis: Mendukung Ekosistem Kendaraan Listrik?}

Perpres No. 55 Tahun 2019 secara umum mengatur tentang percepatan pengembangan industri dan pemberian insentif, penyediaan infrastruktur pengisian listrik dan pengaturan tarif tenaga listrik, teknis kendaraan, perlindungan lingkungan hidup, dan koordinasi pelaksanaan. Perpres ini mengamanatkan pembentukan berbagai regulasi yang lebih teknis. Setidaknya terdapat 14 Peraturan Menteri yang harus ditetapkan agar ketentuan dalam Perpres dapat terlaksana. Menteri yang diberikan delegasi untuk mengatur lebih lanjut adalah Menteri Koordinator Bidang Kemaritiman dan Investasi, ${ }^{57}$ Menteri Perindustrian, ${ }^{58}$ Menteri Perhubungan, ${ }^{59}$ Menteri Keuangan, ${ }^{60}$ Menteri Dalam Negeri, ${ }^{61}$ Menteri Perdagangan, ${ }^{62}$ Menteri Kehutanan dan Lingkungan Hidup, ${ }^{63}$ dan Menteri Energi dan Sumber Daya Mineral. ${ }^{64}$

Menteri Perindustrian mendapatkan porsi paling banyak untuk menetapkan

\footnotetext{
${ }^{56}$ Direktorat Jenderal Minyak dan Gas Bumi, Konversi Mitan ke Gas, (Direktorat Jenderal Minyak dan Gas Bumi, Kementerian Energi dan Sumber Daya Mineral Republik Indonesia, tt), hlm. 33.

${ }^{57}$ Indonesia, Peraturan Presiden Nomor 55 Tahun 2019 tentang Percepatan Program Kendaraan Bermotor Listrik Berbasis Baterai (Battery Electric Vehicle) untuk Transportasi Jalan, LN Tahun 2019 Nomor 146, Pasal 34 ayat 5. ayat 2 .

${ }^{58}$ Ibid., Pasal 2 ayat 3, Pasal 4 ayat 2, Pasal 8 ayat 2, Pasal 11 ayat 3, Pasal 12 ayat 3, dan Pasal 13

${ }^{59}$ Ibid., Pasal 29 ayat 7, Pasal 31 ayat 3 dan 4.

${ }^{60}$ Ibid., Pasal 12 ayat 3.

${ }^{61}$ Ibid., Pasal 19 ayat 3.

${ }^{62}$ Ibid., Pasal 12 ayat 3.

${ }^{63}$ Ibid., Pasal 33.

${ }^{64}$ Ibid., Pasal 27.
} 
peraturan, yakni sebanyak enam Peraturan Menteri Perindustrian. Lainnya, dua Peraturan Menteri Perhubungan dan masing-masing satu Peraturan Menteri untuk sektor Pemerintahan Dalam Negeri, Perdagangan, Keuangan, Lingkungan Hidup, Energi dan Sumber Daya Mineral dan Kemaritiman.

Pembentukan lembaga khusus juga diamanatkan dalam Perpres No. 55 Tahun 2019, bukan hanya satu melainkan dua lembaga dengan nomenklatur Tim Koordinasi Percepatan Program Kendaraan Bermotor Listrik Berbasis Baterai dan Tim Kelompok Kerja Percepatan Program Kendaraan Bermotor Listrik Berbasis Baterai. Menteri Koordinator Bidang Kemaritiman dan Investasi ditugaskan untuk mengatur tata kerja kedua tim tersebut.
Kehadiran lembaga atau tim khusus untuk percepatan program kendaraan listrik ini dapat diartikan sebagai upaya untuk mengharmoniskan kebijakan antar sektor dan kementerian/lembaga terkait. Di sisi lain, kehadiran lembaga khusus ini berpotensi akan menambah rantai birokrasi dan menghambat percepatan program tersebut. Seluruh Kementerian yang terlibat dalam tim ini sebaiknya memastikan bahwa keberadaan tim khusus berdampak positif terhadap percepatan produksi dan penggunaan kendaraan listrik di Indonesia. ${ }^{65}$

${ }^{65} \mathrm{Hal}$ ini sesuai dengan Pidato Presiden Republik Indonesia pada Sidang Paripurna MPR RI dalam rangka Pelantikan Presiden dan Wakil Presiden Terpilih Periode 2019-2024. Jakarta, 24 Oktober 2019. 
Proyeksi Masa Depan Kendaraan Listrik di Indonesia: Analisis Perspektif Regulasi dan Pengendalian

Dampak Perubahan Iklim yang Berkelanjutan

Gambar 1. Struktur Peraturan Pelaksana Perpres No. 55 Tahun 2019

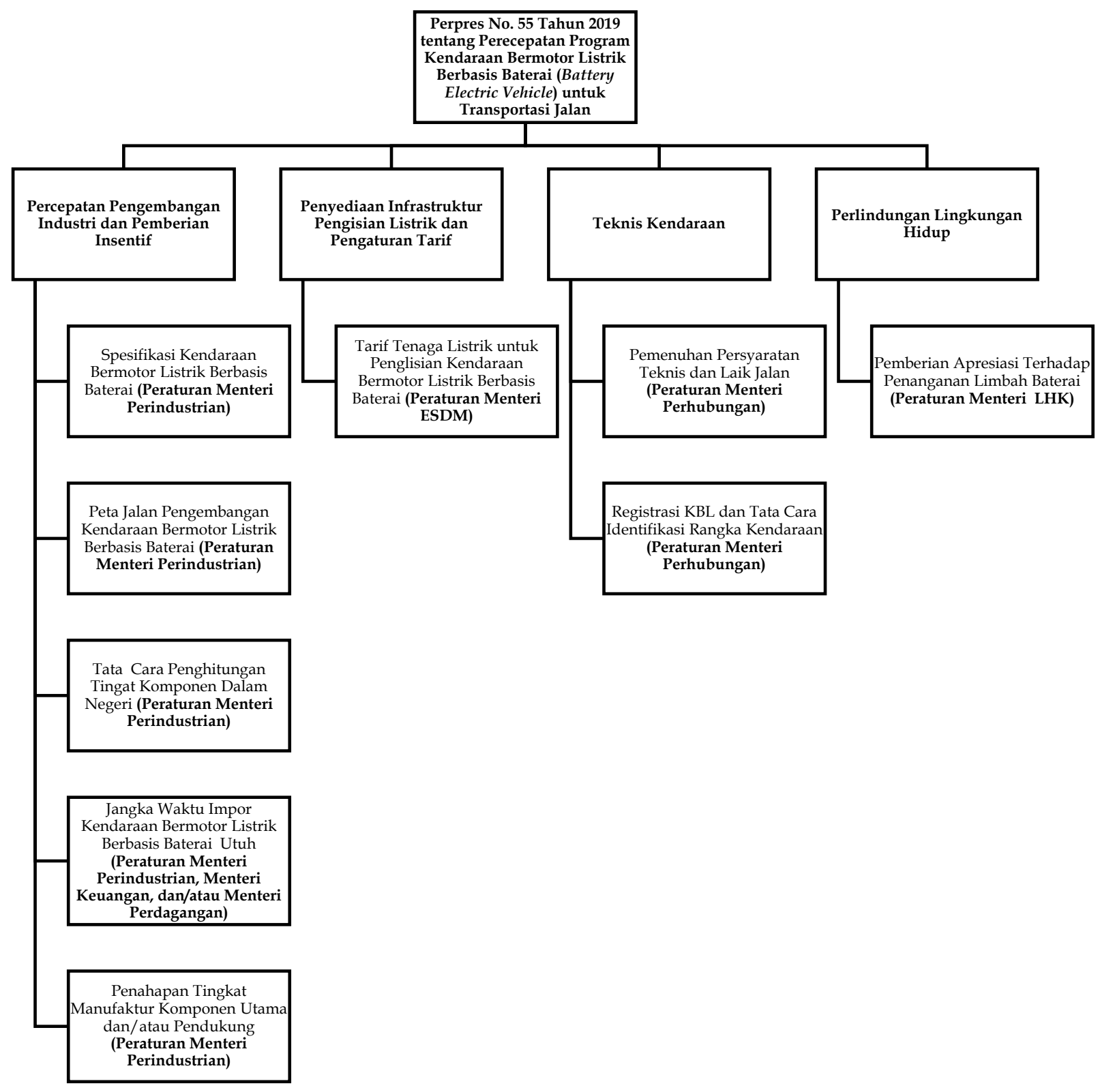

Sumber: Perpres No. 55 Tahun 2019 (Diolah oleh Penulis) 
Gambar menunjukkan bahwa Perpres No. 55 Tahun 2019 memang lebih menitikberatkan aspek industri dan kelaikan kendaraan untuk digunakan secara masif. Ketentuan tentang aspek lingkungan hidup yang diatur dalam Perpres sangat minim dan memberikan kesan tidak dijadikan prioritas. Eksistensi populasi kendaraan listrik di Indonesia dan bahkan seluruh dunia sangat memberikan kontribusi baik langsung maupun tidak langsung bagi lingkungan hidup, khususnya pengendalian dampak perubahan iklim. ${ }^{66}$

Perpres mobil listrik dan segenap peraturan teknisnya seharusnya mampu menciptakan ekosistem hukum yang layak dan komprehensif untuk mendukung perkembangan serta pertumbuhan kendaraan listrik di Indonesia. Dimensi yang perlu diperhatikan bukan hanya industri semata melainkan juga aspek lain khususnya lingkungan hidup yang secara historis mendorong berkembangnya teknologi kendaraan listrik.

Pendapat menarik diungkapkan oleh Guru Besar Emeritus Hukum Energi pada Universitas Adelaide, Australia, yaitu Adrian J. Bradbrook. Setidaknya terdapat lima alasan esensial teknologi masa depan harus dibentuk oleh eko- sistem hukum dengan kriteria tertentu. Pertama, pengembangan teknologi masa depan sangat membutuhkan investasi, oleh karena itu perlindungan hukum wajib diatur secara adil, rasional, serta melindungi kepentingan hukum konsumen (publik) dan investor. ${ }^{67}$

Kedua, pengembangan energi dengan teknologi dan resiko tinggi membutuhkan rezim hukum yang komprehensif, termasuk pengaturan mengenai pemberian kesempatan bagi swasta untuk berpartisipasi serta hak negara untuk memungut royalti dan melindungi kepentingan nasionalnya. Ketiga, tren teknologi masa depan adalah berkurangnya keterlibatan perusahaan besar. Perusahaan kecil dan individual dapat menjadi investor baik skala lokal maupun nasional dengan perlindungan hukum yang maksimal. ${ }^{68}$

Keempat, edukasi bagi konsumen sangat penting untuk diatur karena teknologi baru akan membutuhkan adaptasi dan kebiasaan baru. Peningkatan kepedulian publik dapat dilakukan dengan promosi dan kampanye yang intensif. Kelima, pemerintah wajib menetapkan rezim hukum teknologi baru yang menggantikan teknologi lama. Oleh karena itu, hukum dan kebijakan tersebut harus menempatkan teknologi baru sebagai

\footnotetext{
${ }^{66}$ Idoan Marciano. Op. Cit. hlm. 39.

${ }^{67}$ Adrian J. Bradbrook, "Creating Law For Next Generation Energy Technologies", Journal of Energy and Environmental Law, (Winter 2011), hlm. 19.

${ }^{68}$ Ibid., hlm. 20.
} 
Proyeksi Masa Depan Kendaraan Listrik di Indonesia: Analisis Perspektif Regulasi dan Pengendalian Dampak Perubahan Iklim yang Berkelanjutan

satu-satunya solusi, bukan sebagai alternatif atau bahkan sebagai cadangan. ${ }^{69}$

Secara umum baik Perpres No. 55 Tahun 2019 maupun peraturan menteri yang telah ditetapkan dan mengatur kendaraan listrik masih belum sepenuhnya memenuhi lima kriteria di atas. Perlindungan hukum bagi konsumen (publik) dan investor belum diatur secara rinci, edukasi dan peningkatan kepedulian publik juga belum jelas diatur. Perangkat regulasi ini juga belum menempatkan kendaraan listrik sebagai satu-satunya solusi bagi publik dalam menggunakan kendaraan. Hal yang telah diatur dengan cukup baik adalah terkait insentif (fiskal dan nonfiskal), keselamatan berkendara, teknis kendaraan, dan teknis penyediaan infrastruktur.

Pemberian kesempatan bagi swasta untuk pengembangan kendaraan listrik juga telah diatur dengan baik, khususnya pada sektor hulu industri produksi kendaraan listrik. Namun demikian, pada sektor hilir yaitu penyediaan infrastruktur pengisian dan penggantian baterai untuk tahap awal akan dilakukan oleh badan usaha milik negara. Pemerintah perlu memikirkan pemberian kesempatan bagi swasta dalam rangka mengembangkan infrastruktur penunjang kendaraan listrik untuk membantu penetrasi teknolo- gi masa depan ke masyarakat Indonesia menjadi semakin cepat.

\section{Masa Depan Kendaraan Listrik dan Pengendalian Dampak Perubahan Iklim di Indonesia}

16 bulan setelah penetapan Perpres Nomor 55 Tahun 2019, akhirnya pada 17 Desember 2020 Pemerintah Indonesia melakukan public launching Kendaraan Bermotor Listrik Berbasis Baterai (KBLBB). Dalam Siaran Pers yang dirilis oleh Kementerian Energi dan Sumber Daya Mineral, disebutkan salah satu tujuan percepatan program KBLBB adalah untuk mengurangi tekanan pada neraca pembayaran Indonesia akibat impor bahan bakar minyak. Implikasinya adalah peningkatan ketahanan energi nasional. Oleh karena itu, penggunaan energi terbarukan dan gas sebagai energi primer pada pembangkit listrik menjadi keniscayaan. Sehingga kualitas udara dapat meningkat dan mendukung pengurangan emisi GRK secara nasional. ${ }^{70}$

Pernyataan Menteri Energi dan Sumber Daya Mineral tersebut sesuai dengan target pemanfaatan energi terbarukan pada bauran energi nasional yang ditetapkan dalam Peraturan Presiden Nomor 22 Tahun 2017 tentang Rencana Umum Energi Nasional (RUEN) sebe-

${ }^{69}$ Ibid.

${ }^{70}$ Kementerian Energi dan Sumber Daya Mineral Republik Indonesia, Sambut Era Kendaraan Listrik, Pemerintah Lakukan Public Launching Kendaraan Bermotor Listrik Berbasis Baterai, Siaran Pers Nomor 341. Pers/04/SJI/2020 tanggal 17 Desember 2020. 
sar $23 \% .^{71}$ Namun demikian, realisasi pemanfaatan energi terbarukan pada bauran energi nasional hingga Mei 2020 tercatat masih jauh dari target yaitu sebesar $14,21 \%$ yang didominasi dari energi panas bumi. ${ }^{72}$

Bauran energi terbarukan sebagai energi primer pada pembangkit listrik memang menjadi salah satu syarat mutlak bagi keberlanjutan kendaraan listrik dan berimplikasi pada pengendalian dampak perubahan iklim di Indonesia. Selain itu, setidaknya terdapat empat syarat lain yang harus dipenuhi, Pertama, pengaturan ketat kegiatan pertambangan khusus terkait mineral bahan baku baterai. Peningkatan standar keamanan dan keselamatan lingkungan menjadi wajib dilakukan untuk menghindari kerusakan alam akibat pertambangan.

Kedua, mekanisme pengolahan limbah baterai wajib tersedia terlebih dahulu sebelum adanya peningkatan penggunaan kendaraan listrik secara signifikan. Pemerintah dan publik tentu tidak menginginkan adanya kasus pencemaran lingkungan akibat limbah baterai. Oleh karena itu, instalasi pengolahan limbah perlu diatur dengan rinci dan ketat. Se- bagai catatan, bahwa Perpres Nomor 55 Tahun tidak mengatur secara detail terkait pengolahan limbah.

Ketiga, insentif fiskal (berupa pengurangan atau bahkan penghapusan pajak tertentu) dan non fiskal dilakukan disertai pemberian disinsentif terhadap kendaraan yang menggunakan bahan bakar fosil. Tanpa hal ini, maka transformasi penggunaan kendaraan dari konvensional ke berbasis listrik tidak akan berjalan dengan progresif. Pemerintah juga perlu mempertimbangkan pemberian subsidi harga untuk mempercepat pertumbuhan penggunaan kendaraan listrik. Masalah harga sangat mempengaruhi tingkat penjualan kendaraan listrik pada suatu negara. $^{73}$

Terakhir, pengaturan komprehensif dan terintegrasi terkait kendaraan listrik sejak industri hulu sampai dengan hilir perlu ditetapkan dalam peraturan perundang-undangan yang memberikan kepastian hukum baik bagi investor, publik, maupun bagi lingkungan. Pergantian rezim yang selalu identik dengan bergantinya kebijakan memungkinkan terjadinya gangguan dalam pengembangan kendaraan listrik. Meskipun demiki-

${ }^{71}$ Indonesia, Peraturan Presiden Nomor 22 Tahun 2017 tentang Rencana Umum Energi Nasional Lampiran I, LN Tahun 2017 Nomor 43.

${ }^{72}$ Direktorat Jenderal Energi Baru, Terbarukan, dan Konservasi Energi, Update Kinerja Subsektor EBTKE, (Jakarta: Direktorat Jenderal Energi Baru, Terbarukan, dan Konservasi Energi Kementerian Energi dan Sumber Daya Mineral, 2020).

${ }^{73}$ Jonathan J. Gomez Vilchez dan Christian Thiel, "The Effect of Reducing Electring Car Purchase Incentives in the European Union", World Electric Vehicle Journal, (2019), hlm. 10. 
Proyeksi Masa Depan Kendaraan Listrik di Indonesia: Analisis Perspektif Regulasi dan Pengendalian Dampak Perubahan Iklim yang Berkelanjutan

an, pada tahap tertentu perlu dilakukan penyempurnaan kebijakan jika terjadi kondisi stagnan.

\section{Penutup}

Kendaraan listrik adalah salah satu harapan bagi dunia untuk mengendalikan dampak perubahan iklim. Indonesia berkewajiban untuk berperan aktif dalam upaya tersebut sebagai negara yang berkomitmen dalam Paris Agreement. Oleh karena itu, Indonesia perlu mempelajari keberhasilan Tiongkok, Uni Eropa, dan Amerika Serikat dalam mengimplementasikan regulasi kendaraan listrik.

Perpres No. 55 Tahun 2019 sebagai instrumen hukum utama percepatan program kendaraan listrik perlu memperkuat perlindungan hukum bagi publik dan investor, mengatur promosi dan edukasi kepada publik, serta memastikan tidak adanya tumpang tindih kewenangan antar instansi. Jika diperlukan, RUEN sebaiknya disesuaikan agar lebih progresif pada target produksi dan penggunaan kendaraan listrik, khususnya roda empat.

Pemerintah juga perlu mempertimbangkan untuk mengatur kendaraan listrik melalui bentuk peraturan perundang-undangan yang hierarkinya lebih tinggi dari peraturan presiden, mengingat urgensi pengaturan dan keterlibatan banyak pemangku kepentingan. Peraturan Pemerintah atau bahkan Undang-Undang dapat menjadi pilihan peraturan perundang-undangan yang lebih kuat dan dapat menjangkau seluruh sektor terkait, termasuk pemerintah daerah. Peraturan perundang-undangan terkait kendaraan listrik baik dilevel nasional maupun daerah wajib harmonis dan menunjukkan komitmen yang kuat bagi pengembangan program tersebut.

Regulasi yang diperlukan untuk mendukung percepatan program kendaraan listrik adalah meningkatkan penggunaan energi terbarukan pada pembangkit listrik, mengatur kegiatan pertambangan pada bahan baku baterai secara cermat, menyediakan fasilitas dan sistem pengolahan limbah baterai yang memadai sebelum adanya meningkatkan penggunaan kendaraan listrik, memberikan insentif kepada kendaraan listrik dan disinsentif terhadap kendaraan konvensional, serta mengatur kendaraan listrik secara komprehensif dan terintegrasi dengan peraturan perundang-undangan yang memberikan kepastian hukum baik bagi investor, publik, dan lingkungan. Jika tidak meregulasi lima hal tersebut maka akan menjadi bom waktu bagi kondisi lingkungan hidup dan pengendalian dampak perubahan iklim. Kondisi seperti ini tidak menjadikan kendaraan listrik sebagai solusi, justru berpotensi menjadi masalah baru.

Negara wajib memastikan bahwa kebijakan transformasi energi sebagai upaya pengendalian dampak perubahan 
Jurnal Hukum Lingkungan Indonesia, Vol. 7, No. 2, 2021: Halaman 197 - 220

iklim bukan hanya business as usual semata, perlu adanya intervensi yang konsisten dan terintegrasi. Jika tidak, maka Indonesia akan kurang berkontribusi dalam pengendalian dampak perubahan iklim dan hanya dapat menjadi penonton perubahan modernisasi energi di dunia. 
Proyeksi Masa Depan Kendaraan Listrik di Indonesia: Analisis Perspektif Regulasi dan Pengendalian Dampak Perubahan Iklim yang Berkelanjutan

\section{DAFTAR PUSTAKA}

\section{Peraturan perundang-undangan}

Indonesia. Undang-Undang Pembentukan Peraturan Perundang-undangan, UU No. 12 Tahun 2011, LN Tahun 2011 No.82, TLN No. 5234).

Undang-Undang Pengesahan Paris Agreement to the United Nations Framework Convention on Climate Change (Persetujuan Paris atas Konvensi Kerangka Kerja Perserikatan Bangsa-bangsa Mengenai Perubahan Iklim), UU No. 16 Tahun 2016, LN Tahun 2016 Nomor 204, TLN No. 5939)

Peraturan Presiden Rencana Umum Energi Nasional, Perpres No. 22 Tahun 2017, LN Tahun 2017 No. 43).

Peraturan Presiden Percepatan Program Kendaraan Bermotor Listrik Berbasis Baterai (Battery Electric Vehicle) untuk Transportasi Jalan, Perpres No. 55 Tahun 2019, LN Tahun 2019 No. 146).

\section{Buku}

Adiatma, Julius Christian dan Idoan Marciano. Ringkasan untuk Para pembuat Kebijakan: Peranan Kendaraan Listrik dalam Dekarbonisasi Sektor Transportasi Darat Indonesia. Jakarta: Institute for Essential Services Reform. 2020.

The Role of Electric Vehicles in Decarbonizing Indonesia's Road Transport Sector. Jakarta: Institute for Essential Services Reform. 2020.

Canis, Bill et.al., "Vehicle Electrification: Federal and State Issues Affecting
Deployment,". Congressional Research Service. 2019.

Direktorat Jenderal Pengendalian Perubahan Iklim. Laporan Inventarisasi Gas Rumah Kaca dan Monitoring, Pelaporan, dan Verifikasi 2020. Jakarta: Direktorat Jenderal Pengendalian Perubahan Iklim, Kementerian Lingkungan Hidup dan Kehutanan Republik Indonesia. 2020.

Statistik 2019. Jakarta: Direktorat Jenderal Pengendalian Perubahan Iklim, Kementerian Lingkungan Hidup dan Kehutanan Republik Indonesia. 2020.

Gordon, Deborah et.al. Policy Priorities for Advancing the U.S. Electric Vehicle Market. Washington D.C: Carnegie Endowment for International Peace Publication Department. 2012.

Hamilton, Jamie, et al. Electric Vehicles Setting a Course for 2030. London: Deloitte Insights. 2020.

He, Hui et al. Assessment of Electric Car Promotion Policies in Chinese Cities. Washington DC: International Council on Clean Transportation. 2018.

Howell, Sabrina et.al. Leapfrogging or Stalling Out? Electric Vehicles in China. Cambridge: Harvard Kennedy School. 2015.

Indrati S, Maria Farida. Ilmu Perundang-undangan Jenis, Fungsi, dan Materi Muatan. Yogyakarta: Penerbit Kanisius. 2019. 
International Energy Agency, "Global EV Outlook 2020: Entering the Decade of Electric Drive?," International Energy Agency. 2020.

Intergovermental Panel on Climate Change, Global Warming of $1.5^{\circ} \mathrm{C}$ an IPCC Special Report on the impacts of global warming of $1.5{ }^{\circ} \mathrm{C}$ pre-industrial levels and related global greenhouse gas emission pathways, context of strengthening the global response to the threat of climate change, sustainable development, and efforts to eradicate poverty Summary for Policymakers. Switzerland: Intergovermental Panel on Climate Change. 2018.

Manan, Bagir. Teori dan Politik Konstitusi. Yogyakarta: FH UII Press. 2003.

Marciano, Idoan. Mengembangkan Ekosistem Kendaraan Listrik di Indonesia Pelajaran dari Pengalaman Amerika Serikat, Norwegia, dan Cina. Jakarta: Institute for Essential Services Reform. 2021. Niestadt, Maria dan Amalie Bjornavold, "Electric Road Vehicles in the European Union: Trends, Impacts, and Policies," European Parliament Briefing. 2019.

Wang Tao. "Recharging China's Electric Vehicle Policy," Carnegie-Tsinghua Center for Global Policy, Policy Outlook. 2013.

Wappelhorst, Sandra et.al. Analyzing Policies to Grow the Electric Vehicle Market in European Cities. Berlin: International Council on Clean Transportation White Paper. 2020.

\section{Artikel jurnal/media massa}

Bradbrook, Adrian J. “Creating Law For Next Generation Energy Technologies," Journal of Energy and Environmental Law, Winter 2011.

Chan, C. C. "The Rise and Fall of Electric Vehicles in 1828-1930: Lessons Learned," Proceedings of the IEEE, Vol. 101, No.1, Januari, 2013.

Csamangó, Erika Farkas. “The Legal Environment of Electromobility in Hungary," Journal of Agricultural and Environmental Law, 2020.

Coffin, David dan Jeff Horowitz. "The Supply Chain for Electric Vehicle Batteries," United States International Trade Commission, Journal of International Commerce and Economics, 2018.

Ding, Ning, K. Prasad, dan T.T.Lie, "The Electric Vehicle: a Review," International Journal of Electric and Hybrid Vehicle, Januari 2017.

Jurdi, Fajlurrahman. “Format Kekuasaan Presiden dalam UUD NRI 1945 (Relasi Horizontal dan Vertikal kekuasaan Presiden dalam Sistem Presidensial)," Jurnal Amanna Gappa, Vol 25 No. 2, September 2017.

Listiningrum, Prischa. "Eksistensi dan Kedudukan Peraturan Presiden dalam Hierarki Peraturan Perundang-undangan di Indonesia," Jurnal Arena Hukum, Vol 12 No. 2, Agustus 2019.

Vilchez, Jonathan J. Gomez dan Christian Thiel, "The Effect of Reducing Electring Car Purchase Incentives in the 
Proyeksi Masa Depan Kendaraan Listrik di Indonesia: Analisis Perspektif Regulasi dan Pengendalian Dampak Perubahan Iklim yang Berkelanjutan

European Union," World Electric Vehicle Journal, 2019.

van Mierlo, Joeri. “The World Electric Vehicle Journal, The Open Access Journal for the e-Mobility Scene," World Electric Vehicle Journal, 2018.

Perry, Amanda. “An Ideal Legal System for Attracting Foreign Direct Investment? Some Theory and Reality," American University International Law Review, Vol 15, Issue 6, 2000.

Poczter, Sharon L. dan Luka M. Jankovic. "General Motors: The Electric Revolution," Journal of Business Case Studies, Second Quarter 2014.

Santoso, Arif Dwi. "Penerapan Biaya Lingkungan dalam Perlindungan Sumberdaya Alam dan Kelestarian Lingkungan," Jurnal Rekayasa Lingkungan, Vol. 11, No. 1, Juni 2018.

Xu, C., Dai, Q., Gaines, L. et al., "Future material demand for automotive lithium-based batteries." Communication Materials, https://doi.org/10.1038/ s43246-020-00095-x. 2020.

Yuanan Hu, et.al., "Retired Electric Vehicle (EV) Batteries: Integrated Waste Management and Research Needs," American Chemical Society, Environmental Science and Technology. 2017.

\section{Lain-lain}

Badan Nasional Penanggulangan Bencana, https://www.bnpb.go.id/infografis/kejadian-bencana-tahun-2019, diakses tanggal 8 Februari 2021.

Badan Pusat Statistik, "Perkembangan Jumlah Kendaraan Bermotor Menu- rut Jenis (Unit) 2017-2019", https:// www.bps.go.id/indicator/17/57/1/ jumlah-kendaraan-bermotor.html, diakses 2 Februari 2021.

Direktorat Jenderal Minyak dan Gas Bumi, Konversi Mitan ke Gas. Direktorat Jenderal Minyak dan Gas Bumi, Kementerian Energi dan Sumber Daya Mineral Republik Indonesia, tanpa tahun.

Direktorat Jenderal Energi Baru, Terbarukan, dan Konservasi Energi. Update Kinerja Subsektor EBTKE. Jakarta: Direktorat Jenderal Energi Baru, Terbarukan, dan Konservasi Energi Kementerian Energi dan Sumber Daya Mineral. 2020.

European Commission. "A European Strategy for Low-Emission Mobility." European Commission, Communication from the Commission to the European Parliament, The Council, The European Economic and Social Committee and the Committee of the Regions. 2016.

Hui He, China New Energy vehicle Market and Policies. The International Council on Clean Transportation. 2020.

International Energy Agency, United States-Policies and Legislation, http:// www.ieahev.org/by-country/united-states-policy-and-legislation/. Diakses 15 Februari 2021.

Iskan, Dahkan. "Manufacturing Hope 123: Main-Main Nasib Ahli yang Mahal", https://www.jpnn.com/news/ main-main-nasib-ahli-yang-mahal?page=3, diakses 2 Februari 2021. 
Jong, Hans Nicholas, “Indonesia Won't Sacrifice Economy for More Ambitious Emissions Cuts", https://news. mongabay.com/2020/04/indonesia-emissions-reduction-climate-carbon-economy-growth/, diakses 8 Februari 2021.

Kementerian Energi dan Sumber Daya Mineral Republik Indonesia. Sambut Era Kendaraan Listrik, Pemerintah Lakukan Public Launching Kendaraan Bermotor Listrik Berbasis Baterai. Siaran Pers Nomor 341.Pers/04/SJI/ 2020 tanggal 17 Desember 2020.

Kurniawan, Ruly. "Pelan tapi Pasti, Jumlah Kendaraan Listrik di Indonesia Mencapai 2.278 Unit", https://otomotif.kompas.com/ read/2020/09/09/090200215/pelan-tetapi-pasti-populasi-kendaraan-listrik-di-indonesia-2278-unit, diakses 2 Februari 2021.

McKinsey, McKinsey Electric Vehicle Index: Europe Cushions a Global Plunge in EV Sales, https://www.mckinsey.com/ industries/automotive-and-assembly/our-insights/mckinsey-electric-vehicle-index-europe-cushions-a-global-plunge-in-ev-sales\#, diakses 15 Februari 2021.

Moriarty, Patrick dan Stephen Jia Wang. "Can Electric Vehicles Deliver Energy and Carbon Reductions?," (disampaikan pada The $8^{\text {th }}$ International Conference on Applied Energy Proceedings), 2017.

Pusparisa, Yosepha. "Rapor Indonesia Menahan Laju Perubahan Iklim", ht- tps://katadata.co.id/arsip/analisisdata/602de2e0ee7f6/rapor-indonesia-menahan-laju-perubahan-iklim, diakses 31 Maret 2021.

Reuters, Indonesia says in early talks with Tesla on potential investment, https://www.reuters.com/article/ us-tesla-indonesia/indonesia-says-in-early-talks-with-tesla-on-potential-investment-idINKBN26Q16I, diakses 11 Februari 2021.

Vincent Fabian Thomas, Potensi Investasi Tesla Terganjal Karena Indonesia Tak Ramah ESG, https://tirto.id/potensi-investasi-tesla-terganjal-karena-indonesia-tak-ramah-esg-gaa9, diakses 11 Februari 2021. 